\title{
Properties of Aluminum Anodes of Various Compositions*
}

\author{
Yoshio Yokota**
}

\section{Introduction}

In the previous paper ${ }^{1)}$, it was reported that aluminum anode was practical for the batteries of reserve type, and that aluminum was electically dissolved well, in the electrolyte containing $\mathrm{Cl}^{-}$.

In general, aluminum as cell anode almost have not been used. Many patents and reports for aluminum anode have been published as reported in the previous paper, ${ }^{2)}$ but, aluminum anode have never been used for practical purposes.

Glicksman introduced the results of corrosion study mainly concerning with natural potential and utilization of anode of the alloy of aluminum and zinc in the electrolytes of various compositions in his summarized report $\mathrm{t}^{3)}$ on zinc, magnesium, and aluminum anode in primary cells.

Furthermore, Hisamatsu investigated on the relation between current density and utilization of amalgamated aluminum for the purpose of using aluminum for boosting anode to prevent corrosion of hull. Then, he concluded that ${ }^{4}$ ) amalgamated aluminum should be used in discharge of high current density, because in discharge of low current desity its utilization of $\mathrm{Al}^{+3}$ is not good and dissolution reaction of $\mathrm{Al}^{+1}$ will occur.

Okamoto et al. measured polarization characteristic of aluminum anode by special rapid method. And, in this report, steady-state potential of anode was constant in spite of current density (shown as $D_{A}$, in this paper), and more dissolution of anode than the one due to the electrochemical reaction was observed, dut to the abnormal dissolution of aluminum anode: and it was concluded that ${ }^{5}$ ) self corrosion reaction was promoted by the rupture of protective film of aluminum.

All of these studies were carried out from the viewpoint of the corrosion or the anti-corrosion, but no attempts have been made for applying aluminum to anode of reserve battery.

In this report, generated current and anode potential per unit area of anode was measured for the aluminum anodes of various composion by the external power source method or Galvanic Cell Method, and then the relations between $D_{A}$ and potential were examined.

\section{Experiment and Discussion}

\section{Measurement by External Power Source Method Under the following experimental} conditions and at the use of the platinum cathode and aluminum anode, constant-current discharge was carried out for various $D_{A}$ by the external power source method, and the relations between $D_{A}$ and potential were examined for the various discharge time, and then the utilization of anode was measured.

\subsection{Materials for experiment}

Cathode : Platinum panel of $2 \mathrm{~cm}^{2}(1 \times 2 \mathrm{~cm})$ and $0.5 \mathrm{~mm}$ thick.

Anode : Aluminum panel of $2 \mathrm{~mm}$ thick was cut into $15 \times 20 \mathrm{~mm}$, and this panel was settled in anode magazine as shown in Fig. 1; and the effective surface area of this anode was $1 \mathrm{~cm}^{2}(1 \times 1 \mathrm{~cm})$

Aluminum for experiment was as follows:

$\begin{array}{lcll}\mathrm{Al} & 99.33 \% & \mathrm{Fe} & 0.34 \% \\ \mathrm{Cu} & 0.07 & \mathrm{Mg} & 0.01 \\ \mathrm{Si} & 0.22 & & \end{array}$

\footnotetext{
* Study on Reserve Battery (Part 2), Study on Aluminum Anode (No.2)

** Mizuguchi Lab., Tokyo Inst. of Tech. Okayama, Meguro-ku, Tokyo

Toyo Dry Battery Co. Ltd., Ogumachi, Arakawa-ku, Tokyo

The original written in Japanese can be seen in J. Electrochem. Soc. Japan 28, 603 (1960).
} 


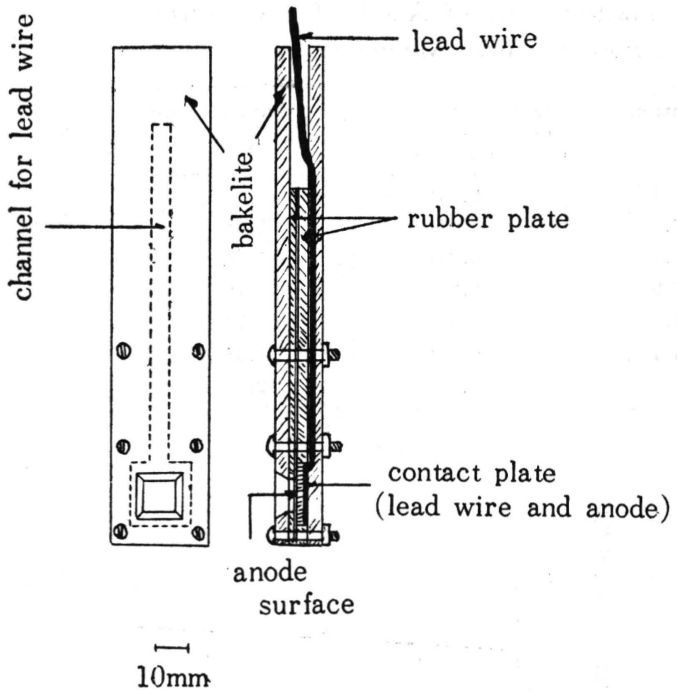

Fig. 1 Anode magazine

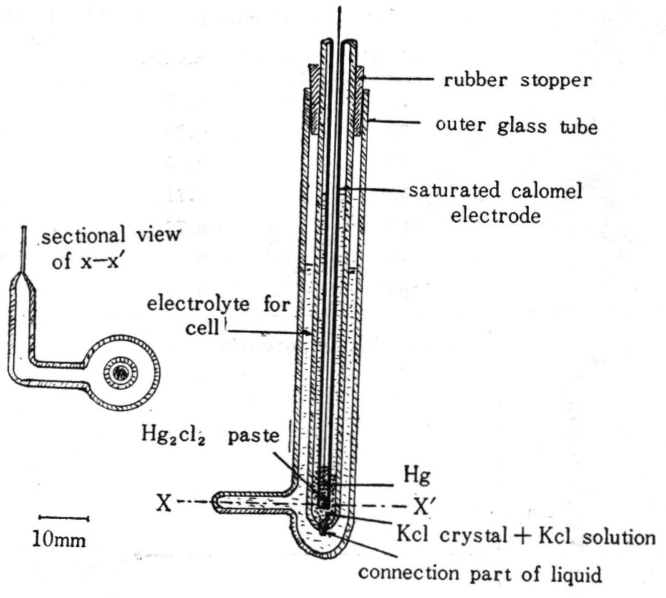

Fig. 2 Scheme of saturated calomel electrode

Before aluminum anode was settled in magazine, electrode surface of this anode was polished with emery paper $\# 600$ and washed with distilled water. After dehydrated and dried with alcohol, the anode was weighed and then used.

Electrolyte : $600 \mathrm{cc}$ of $0.5 \mathrm{M} \mathrm{NaCl}$

Electrolytic Cell : Beaker of $1000 \mathrm{cc}$

1.2 Method of measuring Anode potential during discharge was measured by means of vacuumtube voltmeter, in a thermostatic bath at $25 \pm 1^{\circ} \mathrm{C}$ at intervals of $15 \mathrm{~min}$. Reference electrode (saturated calomel electrode $)^{6)}$ as shown in Fig. 2 was used. The reference electrode was used by placing it in electrolytic cell to keep its temperature same as that of the electrolyte. Luggin capillary was fixed at a constant distance $(1 \mathrm{~mm})$ from anode surface, and ohmic drop between the electrode and Luggin capillary were compensated by calculations.

External resistance was always regulated to keep the definite $D_{A}$. After the end of discharge, aluminum panel was taken out from anode magazine, and the discharge surface was washed with tooth-brush in running water to remove corroded matter, and then weighed after drying.

Utilization rate of anode was calculated* from the theoretical dissolution amount determined by amperage and the practical dissolution amount.

Amount of self-corrosion per $\mathrm{cm}^{2}$ per min** was calculated from the difference of the practical and the theroretical dissolution amounts.

1.3 Experimental results Amperage was defined to $75 \mathrm{mAh}$, and discharge was carried out for various $D_{A}$. The results as shown in Table 1 were obtained.

The utilization rates of anode more than $80 \%$ were obtained, in spite of $D_{A}$. However, amount of self-corrosion increased with increasing $D_{A}$.

Potential change and amperage $\left(D_{A}=20 \mathrm{~mA} / \mathrm{cm}^{2}\right)$, taken from the data in Table 1, is shown in Fig. 3. Potential always gave a very steady value in any discharges at every value of $D_{A}$ as the same in Fig. 3.

The relation between potential and $D_{A}$ after $1 \mathrm{hr}$. from the circuit is summarized as shown in Fig. 4.

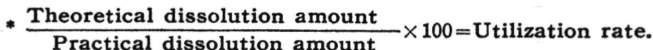

Practical dissolution amount $\times 100$ Utilization rate.

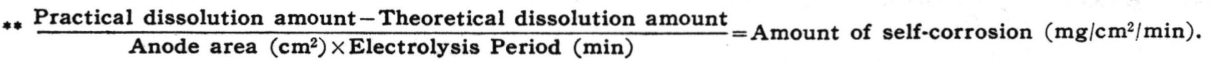


Table 1 Changes of Potential and Utilization Rate of Anode, for Various Discharge Current (External Power Source Method).

\begin{tabular}{c|c|c|c|c}
\hline $\begin{array}{c}\text { Current density } \\
\mathrm{mA} / \mathrm{cm}^{2}\end{array}$ & $\begin{array}{c}\text { Anode potential* } \\
\text { vs. S.C.E. }\end{array}$ & $\begin{array}{c}\text { Utilization of } \\
\text { anode } \\
(\%)\end{array}$ & $\begin{array}{c}\text { Quantity of self } \\
\text { corrosion } \\
\mathrm{mg} / \mathrm{cm}^{2} / \mathrm{min}\end{array}$ & $\begin{array}{c}\text { Terminal voltage } \\
(\mathrm{V})\end{array}$ \\
\hline 20 & -0.72 & 82.4 & 0.024 & 1.10 \\
30 & -0.75 & 87.5 & 0.024 & 1.36 \\
40 & -0.65 & 86.4 & 0.036 & 1.59 \\
50 & -0.71 & 85.5 & 0.048 & 1.78 \\
60 & -0.77 & 84.5 & 0.063 & 1.99 \\
80 & -0.81 & 84.3 & 0.084 & 2.35 \\
100 & -0.97 & 80.8 & 0.133 & 2.70 \\
\hline
\end{tabular}

* Closed circuit potential

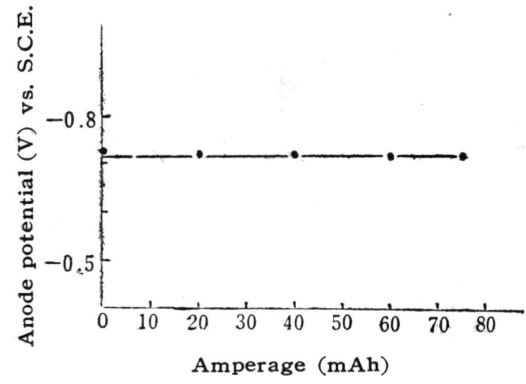

Fig. 3 Relation between anode potential and amperage $\left(D A=20 \mathrm{~mA} / \mathrm{cm}^{2}\right)$

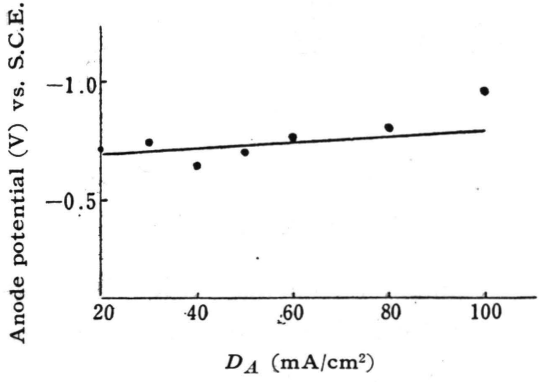

Fig. 4 Relation between anode potential and current density

1.4 Discussion As shown in Table 1 and Fig. 4, potential and utilization rate of anode in discharge had no relation to $D_{A}$, and no great change was observed.

As the result, self-corrosion amount of aluminum anode became larger with increasing $D_{A}$ at amperage of $75 \mathrm{mAhr}$.

2 Measurement by Means of Galvanic Cell Method The change of potential was measured with during discharge with constant current at various $D_{A}$ under the following experimental conditions.

Amperage was $15 \mathrm{mAhr}$ at low $D_{A}$, and $75 \mathrm{mAhr}$ at high $D_{A}$.

2.1. Materials for experiment Cathode: Powder of silver oxide (first grade for chemical use), was mixed well with artificial graphite (300 mesh) in a mortar, at the ratio of 7 to 3 , and pasted with a proper quantity of solution of vinyl chloride adhesives: and then, painted on copper gauze in the thickness of $2 \mathrm{~mm}$. Its effective area was $24 \mathrm{~cm}^{2}$ $(4 \times 6 \mathrm{~cm})$, and the content of silver oxide was $8 \mathrm{~g}$.

This cathode was settled in cathode magazine made of celluloid, as shown in Fig. 5 .

An aperture of $15 \mathrm{~cm}^{2}(5 \times 3 \mathrm{~cm})$ was cut out on the cathode magazine, and a cellophane diaphragm was pasted on this aperture as shown in Fig. 5.

Anode magazine and treatment of surface were the same as shown in section 1.1.

Electrolyte : All reagents were first grade for chemical use, and electrolytes offollowing composition were used.

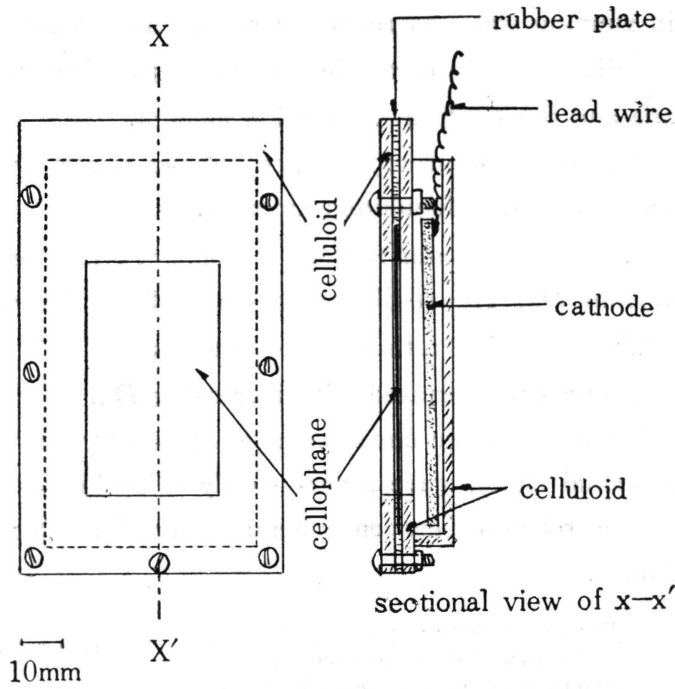

Fig. 5 Cathode magazine 

(A) $0.5 \mathrm{M} \mathrm{NaCl}$
(B) $0.5 \mathrm{M} \mathrm{NaCl}, 0.1 \mathrm{M} \mathrm{HCl}$

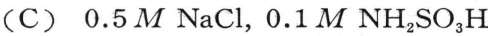

Electrolytic cell: Beaker of $500 \mathrm{cc}$, containing electrolyte of $300 \mathrm{cc}$.

Table 2 Composition of Anode Aluminium (\%)

\begin{tabular}{|c|c|c|c|c|c|c|c|}
\hline $\begin{array}{l}\text { Anode } \\
\text { Component }\end{array}$ & A & B & C & D & $\mathrm{E}$ & F & G \\
\hline $\mathrm{Al}$ & $99.99_{7}$ & 99.33 & $98.33_{5}$ & $95.27_{6}$ & $99.77_{5}$ & 98.65 & $99.99_{7}$ \\
\hline $\mathrm{Cu}$ & 0.0017 & 0.07 & 0.0018 & 0.0016 & 0.2226 & 0.01 & 0.0017 \\
\hline $\mathrm{Si}$ & 0.0010 & 0.22 & 0.0010 & 0.0010 & 0.0010 & 0.06 & 0.0010 \\
\hline $\mathrm{Fe}$ & 0.0008 & 0.34 & 0.0019 & 0.0006 & 0.0015 & 0.08 & 0.0008 \\
\hline $\mathrm{Zn}$ & - & - & 1.66 & 4.72 & - & 1.00 & - \\
\hline Mn & - & 0.03 & - & - & - & - & - \\
\hline $\mathrm{Mg}$ & - & 0.01 & - & - & - & - & - \\
\hline In & - & - & - & - & - & 0.2 & - \\
\hline $\mathrm{Hg}$ & - & - & - & - & - & - & $+*$ \\
\hline
\end{tabular}

* Aluminium surface was amalgamated with $5 \%$ aq. solution of $\mathrm{HgCl}_{2}$ just before use, after Aluminium panel of $\mathrm{A}$ was settled in anode magazine.

\subsection{Method of measuring}

The same as shown in section 1.2.

\subsection{Experimental results}

$D_{A} \cdots \cdots \cdots \cdots \cdots \cdot \ldots+5,10,20,30,40,50 \mathrm{~mA} / \mathrm{cm}^{2}$

Amperage : $2 \sim 10 \mathrm{~mA} / \mathrm{cm}^{2} \cdots \cdots \cdots \cdots \cdots \cdot 15 \mathrm{mAh}$. more than $10 \mathrm{~mA} / \mathrm{cm}^{2} \cdots \cdots \cdots \cdots \cdots .75 \mathrm{mAh}$.

(a) In the case of neutral electrolyte $(0.5 \mathrm{M} \mathrm{NaCl})$ Aluminum of several compositions were discharged under $D_{A}=5 \mathrm{~mA} / \mathrm{cm}^{2}$, and the relation between the change of potential and amperage are shown in Fig. 6.

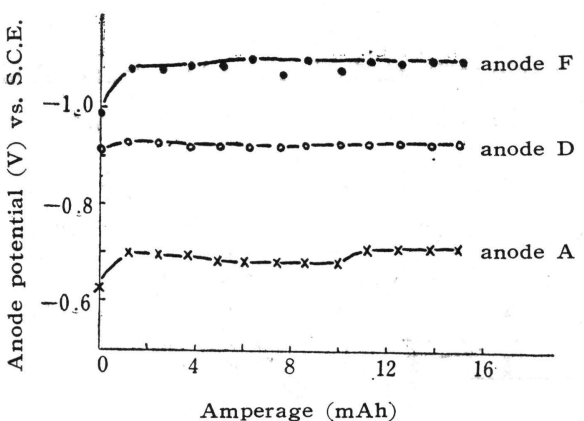

Fig. 6 Relation between anode potential and amperage in various aluminium anodes $\left(D A=5 \mathrm{~mA} / \mathrm{cm}^{2}\right)$

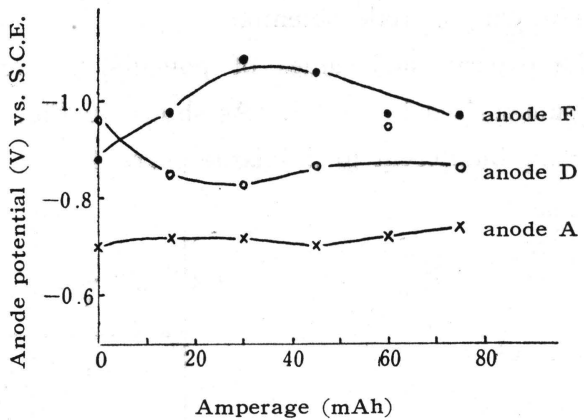

Fig. 7 Relation between anode potential and amperage in various aluminium anodes $\left(D A=30 \mathrm{~mA} / \mathrm{cm}^{2}\right)$

As shown in Fig. 6, each alumimum gave a little positive potential at the start, but arrived to the steady potential in the course of discharge. The relation between potential and amperage during the discharge of anode $A, D$ and $F$ under $D_{A}=30 \mathrm{~mA} / \mathrm{cm}^{2}$ are shown in Fig. 7. As shown in Fig. 7, at aluminum of high purity (for example, anode $A$ ), potential was steady for a long time during the discharge, even though for high $C_{D}$. From these results, the potentials of various anodes after $1 \mathrm{hr}$ from the start of discharge are summarized as shown in Table 3.

(b) In the case of acid electrolyte The relation between $D_{A}$ and potential was studied for $A$ anode in Table 2 discharged in the solution containing hydrochloric acid (B) or containing sulfamic 
Table 3 Relation Between Composition of Aluminium and Current Density, Potential*

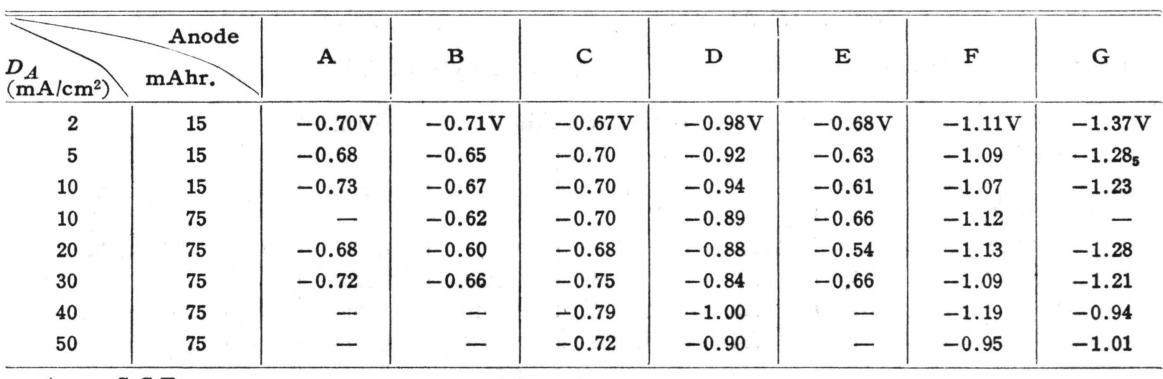

* vs. S.C.E.

Table 4 Relation Between Composition of Electrolyte and Current Density, Anode Potential*

\begin{tabular}{|c|c|c|c|c|}
\hline $\begin{array}{l}D_{A} \\
\left(\mathrm{~mA} / \mathrm{cm}^{2}\right)\end{array}$ & $\begin{array}{r}\text { Composition of } \\
\text { electrolyte } \\
\text { mAhr. }\end{array}$ & $\mathrm{NaCl} 0.5 M$ & $\begin{array}{l}\mathrm{NaCl} 0.5 M \\
\mathrm{HCl} 0.1 M\end{array}$ & $\begin{array}{c}\mathrm{NaCl} 0.5 M, \\
\mathrm{NH}_{2} \mathrm{SO}_{3} \mathrm{H} 0.1 M\end{array}$ \\
\hline 2 & 15 & $-0.70 \mathrm{~V}$ & $-0.72 \mathrm{~V}$ & $-0.70 \mathrm{~V}$ \\
\hline 5 & 15 & -0.68 & -0.75 & -0.72 \\
\hline 10 & 15 & -0.73 & -0.67 & -0.65 \\
\hline 10 & 75 & - & -0.65 & -0.71 \\
\hline 20 & 75 & -0.68 & -0.71 & -0.66 \\
\hline 30 & 75 & -0.72 & -0.51 & -0.70 \\
\hline 40 & 75 & - & -0.69 & -0.63 \\
\hline 50 & 75 & - & -0.69 & -0.74 \\
\hline
\end{tabular}

acid (C). The values of potential after $1 \mathrm{hr}$ from the start of discharge are summarized as shown in Table 4.

\subsection{Discussion}

(a) On electrode potential

The experimental values of potential measured by galvanic cell method are taken from Table 3 and summarized in Fig. 8. As shown in Fig. 8, the potential of aluminum (simple) anode was almost constant, indifferent to discharge current.

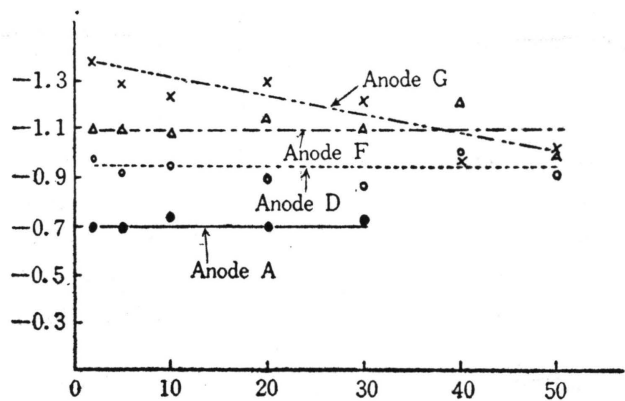

Fig. 8 Relation between anode potential and current density in various aluminium anodes

As will be reported in future, potentials were changed with the increase of $D_{A}$, in the case of the discharge of amalgamated aluminum, zinc or magnesium in the same electrolyte, while in the case of aluminum (anode) showed a specific phenomenon, and this phenomenon will be studied in detail hereafter.

(b) On the method of discharge

The characteristics of potential-current of aluminum anode were studied by the methods of external 
power source and Galvanic Cell Methods. Almost same values of anode potential were obtained by these two different methode, as shown in Tables 1 and 3.

(c) On aluminum alloy

The effect of addition metals for aluminum anode were as follows: At a series of amalgamated aluminum, Al-In alloy and $\mathrm{Al}-\mathrm{Zn}(5 \%)$ alloy, the electrode potential became more positive gradually.

In particular, when only about $0.2 \%$ of indium was added into aluminum potential became considerably more negative, and from this phenomenon, aluminum alloy may be used as the anode of batteries, in future.

As shown in Fig. 7, the relation between potential and $D_{A}$ for amalgamated aluminum anode was different from that of aluminum simple or other aluminum alloys; at the former, potential becomes positive with increasing $D_{A}$.

This phenomenon may be explained as follows: Mechanism of activation of aluminum by mercury may be different from that of zinc or indium alloy, i.e., activation of amalgamated aluminum may be due to the large effective surface occurred by removing effect of oxide film on aluminum surface by mercury.

\section{Conclusion}

By external power source method by the use of aluminum anode of various compositions and platinum cathode or by galvanic cell method by the use of silver oxide as depolarizer, constant-current discharges under $2-100 \mathrm{~mA} / \mathrm{cm}^{2}$ were carried out, and the relations between current density and potential were examined. These results are summarized as follows:

1. At the range of current density of this experiment, almost same potential were obtained by two different methods external power source method and galvanic cell method, so, it is found that the investigation of the characteristics of anode should be possible in any one of two methods.

2. In the range of current density of $2-100 \mathrm{~mA} / \mathrm{cm}^{2}$, potentials of aluminum anode were almost constant, indifferent to the electrolyte composition and the current density.

3. In general, at the use of aluminum of high purity, electrode potential became more positive and generated current became small than at the other electrode, but during the discharge, steady current was observed for a long time. Therefore, this electrode is usable as the anode material of cells required steady potential for a long time.

The potential of $\mathrm{Al}-\mathrm{In}$ or $\mathrm{Al}-\mathrm{Zn}(5 \%)$ alloy has more negative potential than that of high purity aluminum, and so the large current is generated, but the use of these alloys is still under consideration for the practical use.

Amalgamated aluminum showed the potential of almost $1.3 \mathrm{~V}$ (vs. S.C.E.) at the close of circuit, and it is usable as the anode for cells required large potential or large current.

\section{Acknowledgement}

The author expresses his gratitude to Prof. Yoshizawa of Kyoto Univ., and Prof. Mizuguchi of Tokyo Inst. of Tech., for suggesting of this study and to Mr. Katsusaburo Ishiyama, Sp. Manage Direc. of Tokyo Dry Battery Co., and Mr. Itsuro Hirota, Ord. Manage Direc. of the above company, for their permission of publishing this report. The author is indebted to Mr. Minoru Karashima, Mitsubishi Mining Co., for his kindness of obtaining aluminum specimen and to Miss Sawako Kishida who earnestly co-operated in this work.

(Received Feb. 4, 1960) 


\section{Literature :}

1) Y. Yokota, This Journal 28, E-204 (1960).

2) N.C. Cahoon, M.P. Korver, J. Electrochem. Soc. 106, 469 (1959).

3) R. Glicksman, J. Electrochem. Soc. 106, 457 (1959).

4) Y. Hisamatsu, J. Electrochem. Soc. Japan. 27, 184 (1959).

5) G. Okamoto, T. Morozumi, and H. Arai, J. Electrochem. Soc. Japan 27, 437 (1959).

6) H. Hine, J. Electrochem. Soc. Japan 26, 139 (1958). 